\title{
A Consistent Firm Objective When Markets are Incomplete: Profit Maximization
}

\author{
By \\ Tarun Sabarwal ${ }^{1}$ \\ Department of Economics, BRB 1.116 \\ The University of Texas at Austin \\ 1 University Station C3100 \\ Austin TX 78712-0301 USA \\ sabarwal@eco.utexas.edu \\ First Draft: April 2003 \\ This Version: October 14, 2003
}

JEL Numbers: D51, D52

Keywords: Incomplete Markets, Firm Objective, Profit Maximization, Shareholder Preferences

\footnotetext{
${ }^{1}$ Website: http://www.eco.utexas.edu/faculty/sabarwal
} 


\title{
A Consistent Firm Objective When Markets are Incomplete: Profit Maximization
}

\begin{abstract}
In economies with private firm ownership, when markets are incomplete, and firm shareholders change over time, there is no broad agreement on what ought to be a firm's objective. It is shown that ex-post, profit maximization is consistent with shareholder preferences in such economies; that is, along the equilibrium path, in every period and state of the world, every coalition of a firm's shareholders in that period and state approves a profit-maximizing production plan. This result is shown using natural assumptions about shareholder preferences and shareholder control, and it applies to cases when shareholders within a firm and across firms can form coalitions, and when stock trading can be ex-dividend or cum-dividend, and with a combination of both. This result can help provide a foundation for formulating a theory of the firm when markets are incomplete; a theory based on primitives of shareholder preferences and shareholder control that are to be necessarily satisfied in economies with private firm ownership.
\end{abstract}




\section{Introduction}

A theory of the firm in economies with incomplete markets is not yet well-established, partly because there is no broad agreement on some basic questions, such as what ought to be a firm's objective when markets are incomplete. In the standard Arrow-Debreu model with complete markets, a firm's objective is to maximize profits, and a firm's shareholders unanimously support this objective, essentially because it leads to a maximal budget set for each of them. When markets are incomplete, and there is trade over time, both in spot and stock markets, a firm's shareholders can change over time, and as different shareholders in different periods can have different preferences, it is not known what firm objective, as an equilibrium concept, can survive potential conflicts with changing shareholder preferences. Providing a consistent firm objective when markets are incomplete is an important step in understanding the design and organization of productive resources in a private ownership economy with incomplete markets, especially because a complete set of markets does not exist in actual economies. $^{2}$

This paper shows that profit maximization is consistent with shareholder preferences even when markets are incomplete and shareholders are changing over time, in the sense that ex-post, along the equilibrium path, in every time period and state of the world, every coalition of a firm's shareholders in that time period and state of the world approves a profitmaximizing production plan. ${ }^{3}$ That is, in a sense made precise below, along the equilibrium

\footnotetext{
${ }^{2}$ Markets for commodities might not exist for several well-known reasons, including externalities, asymmetric information, legal restrictions, technological limitations, set-up costs, and the extensive number of markets required by the definition of an economic commodity.

${ }^{3}$ In particular, shareholders in every time period and state of the world unanimously approve a profit-
} 
path, no coalition of shareholders can improve on a profit-maximizing plan. The intuition for this result is similar to the intuition for the result for Arrow-Debreu economies; that is, a profit-maximizing production plan provides a maximal extension of every consumershareholder's budget set in each period and state in which a consumer-shareholder can affect production choices, and therefore, if a consumer-shareholder is optimizing over such a budget set, another production plan cannot improve upon this outcome. The analysis here deduces the consistency of profit-maximization by incorporating some basic implications of a relatively realistic process of shareholder control, by deriving shareholder preferences for production plans from more primitive consumer preferences, and by evaluating different production plans using such shareholder preferences along any path that might be realized in equilibrium. The result presented here applies to decentralized, private ownership economies with anonymous stock market trade over time, and with firm ownership separate from control.

Previous work in the theory of incomplete markets has postulated several firm objectives, including firm utility maximization, and different forms of firm market value maximization, and there has been some discussion of how these objectives relate to a firm's shareholders, but such firm objectives have not been formally shown to satisfy some primitive shareholder preferences for production plans. ${ }^{4}$ For example, in the seminal paper by Radner (1972) on incomplete markets and sequential trade, an explicit continuous and strictly concave (but otherwise arbitrary) utility function is postulated for each firm in an economy, and a firm's maximizing production plan.

${ }^{4}$ A notable exception is the model by Ekern and Wilson (1974), and as described in Radner (1974), their model can be formulated as a model with complete markets. 
objective is to choose a production plan to maximize firm utility, but it is not shown if this firm utility is consistent with the preferences of some, or all, or none of a firm's shareholders, and the problem is made more complex when firm shareholders are changing over time.

Drèze (1974), in a two-period model, has postulated a firm objective of maximizing firm value, with firm value defined as the present value of firm profits, and with present value computed using an average of the marginal rates of inter-temporal substitution of firm shareholders in the second period; that is, using the average present value coefficients of final shareholders. As mentioned in Geanakoplos, Magill, Quinzii, and Drèze (1990), this approach has the advantage of being the only criterion which satisfies the first-order conditions of constrained Pareto optimality (as defined in their paper), and as mentioned in Grossman and Hart (1979), there can be a problem in extending this approach to economies with more than two periods, (but confer Bonnisseau and Lachiri (2003) for one such extension.)

Grossman and Hart (1979), in a multi-period model, have postulated the same objective for the firm as has Drèze, but with present value computed using an average of the marginal rates of substitution of firm shareholders in the first period; that is, using the average present value coefficients of the original shareholders. This approach has the advantage of being applicable in a multi-period model, but as mentioned in Geanakoplos, Magill, Quinzii, and Drèze (1990), a focus on original shareholders is reasonable only if future shareholders cannot reverse production plans. This condition appears to be formalized by Grossman and Hart in their postulate of utility-taking behavior, a concept described in their paper as "each consumer anticipates that when a firm alters its production plan, his utility will not change as a result of capital gains and losses per se, expect to the extent that the consumer is an initial shareholder of the firm." 
In the papers mentioned above, a motivation for considering alternative firm objectives originates from a recognition that if firm choices are contrary to shareholder preferences, then managers who control firm operations (such as a board of directors or senior managers) can be replaced by firm shareholders. Concepts of maximizing present value of firm profits are motivated by comparison to the case of complete markets, where initial and final shareholders are the same, where each consumer-shareholder's preferences for production are summarized by her marginal rates of substitution between income now and income in different states in the future, and the collection of these marginal rates of substitution is equalized across consumer-shareholders in equilibrium, and therefore, a firm objective of maximizing present value of profits can be unambiguously defined in terms of these rates, and is consistent with the preferences of each consumer-shareholder. When markets are incomplete, these rates are usually not equalized, and therefore, marginal rates of substitution for different consumer-shareholders yield different present values for firm profits, maximizing different present values can be consistent with the objectives of some shareholders and inconsistent with that of others, and consequently, shareholders have an incentive to block production plans inconsistent with their preferences. It is not clear what firm objective survives a potential shareholder blocking. Against this backdrop, a firm objective of market value maximization postulated by Drèze (1974) and Grossman and Hart (1979) can be rationalized by explaining that each version of present value of firm profits is well-defined, and each version can be possibly expected to survive shareholder blocking by an average shareholder.

This paper explicitly tries to understand and incorporate some basic implications of the process by which shareholders can affect firm decisions. In an economy with private firm ownership and anonymous stock market trade over time, firm shareholders cannot be 
assumed to know the identities of other shareholders, ex-ante. At most, shareholders in a particular period can be assumed, ex-post, to know the identities of other shareholders in that period, perhaps in a shareholder meeting for that period. Moreover, firm shareholders in a particular period can affect firm decisions in that period, (by voting to remove management, if necessary,) they can block a production plan inconsistent with their preferences even if such a plan is preferred by (possibly different) shareholders in a different period, and therefore, for a particular production plan to satisfy a consistent firm objective, whether the plan is based on some average preferences of either initial shareholders, or final shareholders, or shareholders in some other period, such a plan should survive shareholder blocking in every period (more generally, every node)..$^{5}$ Finally, although shareholders in a particular shareholder meeting can approve or block production plans, shareholders can change over time, and therefore, shareholder preferences for production plans can change over time, and as future shareholders can affect future production choices, shareholders in a particular period cannot automatically assume that a firm manager implements a future production plan consistent with existing shareholder preferences. They can, at most, credibly affect the choice of a production plan at a node at which they are firm shareholders.

The result in this paper can be viewed as an ex-post evaluation of the consistency of profitmaximization, as compared to an ex-ante evaluation implicit in previous work. Consider a standard two-period, Radner-GEI economy with incomplete markets, with finitely many

\footnotetext{
${ }^{5}$ Notice that even at a particular node, it is not necessary that shareholders composing a particular average unanimously agree with a plan that maximizes present value based on such an average, and indeed, with some variation in shareholder preferences, such a production plan would not be unanimously approved by these shareholders.
} 
states of the world in the second period, finitely many commodities in each period and state, finitely many firms, and finitely many consumer-shareholders. The process of shareholder control posited here assumes that shareholders in period 1 (that is, original shareholders) can vote on the production plan for period 1, and regardless of which state $s$ is realized, shareholders in period 2 (that is, final shareholders, determined after period 1 stock market trade) can vote on the production plan for period 2, state $s$. Previous results about differing shareholder preferences arise if, as in Drèze (1974), period 2 shareholders (or equivalently, final shareholders, or equivalently, end-of-period 1 shareholders) can implement in period 1 a production plan for period 2, or if, as in Grossman and Hart (1979), period 1 shareholders (or equivalently, original shareholders) can implement in period 1 a production plan for period 2. This is possible, if shareholders implement firm decisions, but this cannot automatically be assumed if firm decisions are implemented by managers who might be accountable to different future shareholders. In such a case, it is shown that if firms maximize profits, then ex-post, regardless of which state $s$ is realized, no coalition of period 1 shareholders opposes this firm objective, and no coalition of period 2 shareholders opposes this objective. Intuitively, if a collection of entrepreneurs know each other and run a firm themselves, (that is, if they know each other and can commit to remain owners in the future,) then there can be differences among them about which plan to follow, based on their equilibrium intertemporal rates of substitution, but if shareholders are separate from managerial control, and present shareholders do not know the identity of future shareholders, and therefore cannot credibly affect future plans, then it is in all shareholders' best interest that firm managers maximize profits.

Profit maximization as a firm objective has several well-known and appealing features 
when markets are complete; it is unanimously supported by a firm's shareholders, it allows for a separation of ownership and control, thereby facilitating the anonymity and smooth operation of decentralized markets, and it does not require a firm manager to possess more analytical ability than a consumer-shareholder. ${ }^{6}$ These features are more desirable in economies with incomplete markets, because with profit maximization as a firm objective, firm production over time can be consistently organized even when firm shareholders are changing over time. In particular, profit maximization does not impose additional informational requirements that arise when firms maximize present value based on shareholder inter-temporal rates of substitution; that is, with separation of ownership and control, and with a firm objective of value maximization, in addition to requirements for profit maximization, a firm is required to correctly predict both the identity of its equilibrium shareholders as well as their equilibrium inter-temporal rates of substitution.

It is noteworthy that this paper does not consider the problem of efficiency of equilibrium allocations when markets are incomplete. As is well-known, when markets are incomplete, competitive equilibria and stock market equilibria might fail to be Pareto efficient (Hart (1975), Stiglitz (1982)). Moreover, with particular definitions of constrained efficiency, competitive equilibria can be constrained Pareto efficient (Diamond (1967)), can fail to be constrained Pareto efficient (Dierker, Dierker, and Grodal (2002)), can generically fail to be constrained Pareto efficient (Geanakoplos and Polemarchakis (1986), Geanakoplos, Magill, Quinzii, and Drèze (1990)), and in a fairly weak sense of constrained efficiency, are Allais-

\footnotetext{
${ }^{6}$ In maximizing profits, firm expectations about prices and firm ability regarding optimization are the same as those required of a consumer. This provides conceptual cohesiveness, because firm decisions are taken by a consumer providing services for managing a firm.
} 
Malinvaud efficient (Sabarwal (2003)). Moreover, this paper focuses on competitive markets. Analysis of firm objectives under oligopolistic markets is presented in Dierker and Grodal (1996), and in Dierker and Grodal (1999).

The next section shows the consistency of profit maximization as a firm objective when markets are incomplete. This is formally shown in the context of Radner-GEI economies, and with natural assumptions about shareholder preferences and shareholder control. The section after that presents some extensions of this basic result, and the last section concludes.

\section{Profit Maximization as a Firm Objective}

The seminal paper by Radner (1972) formalizes a model of an economy in which markets are incomplete in the sense that in each period and state of the world, all commodities for delivery in that period and state of the world can be traded, but some commodites for future delivery cannot be traded. In such an economy there are finitely many consumers, firms, and commodities. Firms are privately owned by consumer-shareholders, and shares of firms are traded in stock markets. In each period and state, a consumer-shareholder can trade only in commodities and firm shares for which markets exist in that period and state. Consumers use firm shares to move income among different time periods, and among different states of the world to finance a consumption plan that they desire most. Radner's model of an economy, and some of its extensions are also referred to as a model of general equilibrium with incomplete markets (GEI model). Such an economy is formalized below. ${ }^{7}$

\footnotetext{
${ }^{7}$ Additional details about such economies are given in Grossman and Hart (1979), and in Magill and Quinzii (1996).
} 
A Radner-GEI economy is formalized as follows. Trade takes place over time, and there is uncertainty. Economic activity takes place over a finite number of elementary time periods, indexed $t=1, \ldots, T$, and a finite number of states of the world, indexed $s=1, \ldots, S$. Each state $s$ is a particular history of the environment from period 1 through period $T$. The events observable in period $t$ are given by a partition $\mathcal{S}_{t}$ of $\{1, \ldots, S\}$. To reflect dependence of actions in period $t$ on events observable in that period, a function on $\{1, \ldots, S\}$ is said to be $\mathcal{S}_{t}$-measurable if it is constant on each event $E_{t} \in \mathcal{S}_{t}$. To reflect the additional availability of information as time goes on, the sequence of partitions, $\mathcal{S}=\left(\mathcal{S}_{t}\right)_{t=1}^{T}$, is taken to be nondecreasing in fineness, and it is termed an information structure. For $t=1, \ldots, T$, let $\mathcal{R}_{t}=\left\{\left(\xi_{t}(s)\right)_{s=1}^{S} \in \Re^{S} \mid \xi_{t}(\cdot)\right.$ is $\mathcal{S}_{t}$-measurable $\}$ be the subspace of $\Re^{S}$ consisting of vectors which are $\mathcal{S}_{t}$-measurable and let $\mathcal{R}=\underset{t=1}{\stackrel{T}{×}} \mathcal{R}_{t}$.

There are a finite number of privately-owned firms, indexed $j=1, \ldots, J$, a finite number of consumer-shareholders, indexed $i=1, \ldots, I$, and in each period $t$, state $s$, a finite number of commodities, indexed $\ell=1, \ldots, L$.

The production technology for firm $j$ is $Y^{j} \subset \underset{t=1}{\underset{T}{\times}} \mathcal{R}_{t}^{L}$. A production plan for firm $j$ is an element $y^{j}=\left(y_{t}^{j}\right)_{t=1}^{T} \in Y^{j}$, and it entails an input-output (or netput) of $y_{t}^{j}(s)_{\ell}$ units of good $\ell$ in period $t$, state $s .{ }^{8}$ A production profile is a collection $y=\left(y^{j}\right)_{j=1}^{J}$ where for each $j, y^{j}$ is a production plan for firm $j$. When convenient, $y_{t}^{j}(s)$ denotes a production plan for firm $j$ in period $t$, state $s$, and $\left(y_{t}^{j}(s)\right)_{j=1}^{J}$ denotes a production profile in period $t$, state s. As usual, each $Y^{j}$ is closed, convex, includes the possibility of inaction, $0 \in Y^{j}$, and satisfies free disposal, $Y^{j} \supset\left(-\underset{t=1}{\stackrel{T}{×}}\left(\mathcal{R}_{t}^{L}\right)_{+}\right)$. Moreover, as usual, there is no aggregate free

\footnotetext{
${ }^{8}$ As usual, negative entries in a production plan are inputs, and positive entries are outputs.
} 
lunch, $\left(\sum_{j} Y^{j}\right) \cap\left(\underset{t=1}{\stackrel{T}{\times}}\left(\mathcal{R}_{t}^{L}\right)_{+}\right)=\{0\}$, and there is aggregate irreversibility of production, $\left(\sum_{j} Y^{j}\right) \cap\left(-\sum_{j} Y^{j}\right)=\{0\}$.

Each firm is privately owned by consumer-shareholders. Firm ownership provides a shareholder a claim on firm profits proportional to her firm shareholding, and firm ownership can be traded in stock markets. Therefore, both a consumer-shareholder's shareholding, and a firm's shareholders can change over time. The shareholding space in period $t \leq T-1$ is $\Theta_{t}=\left\{\theta_{t} \in \mathcal{R}_{t}^{J} \mid 0 \leq \theta_{t} \leq 1\right\}$, that in period $t=T$ is $\Theta_{T}=\{0\} \subset \mathcal{R}_{T}^{J}$, and the shareholding space is $\Theta=\underset{t=1}{\stackrel{T}{\times}} \Theta_{t}$. A shareholding plan for consumer-shareholder $i$ is denoted $\theta^{i}$, it is an element of $\Theta$, and it entails holding a $\theta_{t}^{i, j}(s)$ share of firm $j$ in period $t$, state $s$. The shareholding profile space in period $t \leq T-1$ is $\Theta_{t}^{\Delta}=\left\{\theta_{t} \in \Theta_{t}^{I} \mid\right.$ for every $\left.j, s, \sum_{i} \theta_{t}^{i, j}(s)=1\right\}$, that in period $t=T$ is $\Theta_{T}^{\Delta}=\Theta_{T}^{I}$, and the shareholding profile space is $\Theta^{\Delta}=\underset{t=1}{\times} \Theta_{t}^{\Delta}$. A shareholding profile is an element of the shareholding profile space, it is denoted $\theta=\left(\theta^{i}\right)_{i=1}^{I}$, where $\theta_{t}^{i, j}(s)$ is the shareholding of consumer-shareholder $i$ in firm $j$ in period $t$, state $s$.

The consumption space in period $t$ is $X_{t}=\left(\mathcal{R}_{t}^{L}\right)_{+}$, and the consumption space is $X=$ $\underset{t=1}{\stackrel{T}{\times}} X_{t}$. A consumption plan for consumer-shareholder $i$ is an element $x^{i}=\left(x_{t}^{i}\right)_{t=1}^{T} \in X$, and it entails consumption of $x_{t}^{i}(s)_{\ell}$ units of good $\ell$ in period $t$, state $s$. A consumption profile is a collection $x=\left(x^{i}\right)_{i=1}^{I}$ where for each $i, x^{i}$ is a consumption plan for consumer-shareholder $i$. When convenient, $x_{t}^{i}(s)$ denotes a consumption plan for consumer-shareholder $i$ in period $t$, state $s$, and $\left(x_{t}^{i}(s)\right)_{i=1}^{I}$ denotes a consumption profile in period $t$, state $s$. Each consumershareholder $i$ has a preference relation $\left(\succeq^{i} \subset X \times X\right)$ that is complete, reflexive, transitive, convex, continuous, and strongly monotone $\left(x>\dot{x} \Rightarrow x \succ^{i} \dot{x} .\right)^{9}$ Each consumer-shareholder

\footnotetext{
${ }^{9}$ The notions of indifference $\left(\sim^{i}\right)$ and strict preference $\left(\succ^{i}\right)$ are the usual ones.
} 
$i$ has a consumption endowment $w^{i}=\left(w_{t}^{i}\right)_{t=1}^{T} \in X$, and a shareholding endowment $\theta_{0}^{i} \in \Theta_{1}$, such that the collection of consumption endowments satisfies $\inf _{i} w^{i} \gg 0$, and the collection of shareholding endowments satisfies $\theta_{0}=\left(\theta_{0}^{i}\right)_{i=1}^{I} \in \Theta_{1}^{\Delta}$.

Prices of commodities and firms are defined as follows. The price space in period $t \leq$ $T-1$ is $\Delta_{t}=\left\{\left(p_{t}, q_{t}\right) \in\left(\mathcal{R}_{t}^{L+J}\right)_{+} \mid\right.$for every $\left.s, \sum_{\ell} p_{t}(s)_{\ell}+\sum_{j} q_{t}(s)_{j}=1\right\}$, and that in period $t=T$ is $\Delta_{T}=\left\{\left(p_{T}, 0\right) \in\left(\mathcal{R}_{T}^{L+J}\right)_{+} \mid\right.$for every $\left.s, \sum_{\ell} p_{T}(s)_{\ell}=1\right\}$. The price space is $\Delta=\underset{t=1}{\stackrel{T}{\times}} \Delta_{t}$. A price system is an element $(p, q) \in \Delta$, with $p_{t}(s)_{\ell}$ the price of a unit of good $\ell$ in period $t$, state $s$, and $q_{t}(s)_{j}$ the price of firm $j$ in period $t$, state $s$.

For a price system $(p, q)$, and a production plan $y^{j}$ for firm $j$, the profit to firm $j$ in period $t$, state $s$ is $p_{t}(s) y_{t}^{j}(s)$, and the profit to firm $j$ is $p y^{j}=\sum_{s, t} p_{t}(s) y_{t}^{j}(s)$. A production plan $y^{j}$ maximizes profits over $Y^{j}$ if $p y^{j}=\max _{y^{j} \in Y^{j}} p y^{j}$.

For a price system $(p, q)$, a production profile $y=\left(y^{j}\right)_{j=1}^{J}$, and a consumption-shareholding plan $\left(x^{i}, \theta^{i}\right)$ for consumer-shareholder $i$, the disposable income of $i$ in period $t$, state $s$ is

$$
W^{i}(p, q, y)_{t}(s)=p_{t}(s) w_{t}^{i}(s)+q_{t}(s) \theta_{t-1}^{i}(s)+\sum_{j} \theta_{t-1}^{i, j}(s) p_{t}(s) y_{t}^{j}(s)
$$

A consumption-shareholding plan $\left(x^{i}, \theta^{i}\right)$ is $(p, q, y)$-affordable for consumer-shareholder $i$, if in every period $t$, state $s, p_{t}(s) x_{t}^{i}(s)+q_{t}(s) \theta_{t}^{i}(s) \leq W^{i}(p, q, y)_{t}(s) .{ }^{10} \quad$ A consumershareholder's budget set consists of all consumption and shareholding plans that are af-

\footnotetext{
${ }^{10}$ Notice that as in Radner (1972), and in Drèze (1974) and Grossman and Hart (1979), a $\theta_{t-1}^{i, j}(s)$ shareholding by consumer-shareholder $i$ in firm $j$ in period $t-1$, state $s$ provides her with a $\theta_{t-1}^{i, j}(s)$ share of profits of firm $j$ in period $t$, state $s$, (and she continues to receive a share of profits in future periods to the extent that she continues shareholding in this firm.) This implies, of course, that profits in each period are distributed to shareholders as dividends. Moreover, this is consistent with ex-dividend stock trading. The results here remain true with cum-dividend stock trading, as explained in the next section.
} 
fordable, and her demand set consists of those plans in the budget set that are optimal with respect to her preference relation. Formally, for a price system $(p, q)$, and a production profile $y=\left(y^{j}\right)_{j=1}^{J}$, the budget set for consumer-shareholder $i$ is

$$
B^{i}(p, q, y)=\left\{\left(x^{i}, \theta^{i}\right) \in X \times \Theta \mid\left(x^{i}, \theta^{i}\right) \text { is }(p, q, y) \text {-affordable }\right\},
$$

and the demand set for consumer $i$ is

$$
D^{i}(p, q, y)=\left\{\left(x^{i}, \theta^{i}\right) \in B^{i}(p, q, y) \mid\left(\dot{x}^{i}, \dot{\theta}^{i}\right) \in B^{i}(p, q, y) \Rightarrow x^{i} \succeq^{i} \dot{x}^{i}\right\}
$$

\section{A Radner-GEI economy is a collection}

$$
\left\{\mathcal{S},\left(Y^{j}\right)_{j=1}^{J},\left(\succeq^{i}, w^{i}, \theta_{0}^{i}\right)_{i=1}^{I}\right\}
$$

where $\mathcal{S}=\left(\mathcal{S}_{t}\right)_{t=1}^{T}$ is an information structure, $Y^{j}$ is a production technology for firm $j$, and $\left(\succeq^{i}, w^{i}, \theta_{0}^{i}\right)$ is the preference relation and consumption-shareholding endowment of consumershareholder $i$. ARadner equilibrium is a collection $\left(p, q ; y=\left(y^{j}\right)_{j=1}^{J} ;\left(x^{i}, \theta^{i}\right)_{i=1}^{I}\right)$, where $(p, q)$ is a price system, for every $j, y^{j}$ maximizes profits over $Y^{j}$, for every $i,\left(x^{i}, \theta^{i}\right) \in$ $D^{i}(p, q, y), \quad \sum_{i=1}^{I} x^{i}=\sum_{i=1}^{I} w^{i}+\sum_{j=1}^{J} y^{j}$, and $\theta=\left(\theta^{i}\right)_{i=1}^{I} \in \Theta^{\Delta}$. In other words, a Radner equilibrium is a collection of prices, one set for each period and state when markets for trade are open, a production profile, and a consumption and shareholding profile, such that firms are maximizing profits, consumers are maximizing preferences, and in every period and state, all consumption markets are clearing, and all firm shares are held by consumershareholders. ${ }^{11}$ When convenient, a consumption and production profile $\left(\left(x^{i}\right)_{i=1}^{I},\left(y^{j}\right)_{j=1}^{J}\right)$ is

\footnotetext{
${ }^{11}$ For existence of equilibrium with bounds on short sales, see Radner (1972), and Grossman and Hart (1979), and for generic existence of equilibrium without bounds on short sales, see Duffie and Shafer (1985), and Duffie and Shafer (1986).
} 
an allocation if $\sum_{i=1}^{I} x^{i}=\sum_{i=1}^{I} w^{i}+\sum_{j=1}^{J} y^{j}$, and a consumption and production profile $\left(\left(x_{t}^{i}(s)\right)_{i=1}^{I},\left(y_{t}^{j}(s)\right)_{j=1}^{J}\right)$ in period $t$, state $s$ is an allocation in period $t$, state $s$, if $\sum_{i=1}^{I} x_{t}^{i}(s)=$ $\sum_{i=1}^{I} w_{t}^{i}(s)+\sum_{j=1}^{J} y_{t}^{j}(s)$. With this terminology, a consumption and production profile $\left(\left(x^{i}\right)_{i=1}^{I},\left(y^{j}\right)_{j=1}^{J}\right)$ in a Radner equilibrium is an allocation, and consequently, it is an allocation in every period $t$, state $s$.

The main result in this paper is that in economies with private firm ownership, when markets are incomplete, and firm shareholders can change over time, profit maximization remains, ex-post, a firm objective consistent with shareholder preferences. The formal analysis includes postulating shareholder control over firm decisions, deriving shareholder preferences for production plans from consumer preferences, and showing that along the equilibrium path in a Radner equilibrium, no coalition of shareholders wants to deviate from a profitmaximizing production plan. Details are as follows.

As mentioned above, in an economy with private firm ownership, a firm's production choice needs to be somewhat aligned with shareholder preferences, and with trade over time in stock markets, any such alignment is made more complex, because shareholders of a firm can change over time, and therefore, shareholder preferences for production can change over time. To see that a profit-maximizing production plan can be aligned with shareholder preferences, it is important, as a first step, to understand the process by which shareholders might be able to exercise control over firm decisions, and to formalize an idea of when a production plan might be preferred by a coalition of consumer-shareholders. With anonymous trading in stock markets, shareholders in a given period cannot be assumed to know the identities of other shareholders, except possibly when they interact with other shareholders in a shareholder meeting. In this sense, exercise of shareholder control in a 
given period (and state) is limited, at most, to shareholders in that period (and state). Moreover, as future firm shareholders can affect future firm choices, existing shareholders can be credibly assumed only to affect the firm's current period production plan. Therefore, to formalize the concept of shareholder control, it is assumed that (1) there is a shareholder meeting in every period (and state), and at this meeting, firm shareholders in that period (and state) can form voting coalitions and vote on a firm's future production plan, (2) a shareholder in a given period (and state) does not know if another consumer will be a shareholder in a different period (or state), (3) a single future shareholder cannot affect a firm's future production plan, and consequently, (4) shareholders in a given period can credibly affect only the firm's current period production plan.

Shareholder control is exercised as follows. For expositional clarity, suppose, in this paragraph, that there is no uncertainty. As mentioned above, for a period $\hat{t}=1, \ldots, T$, a $\theta_{\hat{t}-1}^{i, j}$ shareholding by consumer-shareholder $i$ in firm $j$ provides her with a $\theta_{\hat{t}-1}^{i, j}$ share of firm $j$ profits in period $\hat{t}$. This is consistent with ex-dividend stock trading; that is, a seller of firm share in period $\hat{t}-1$ keeps her share of firm profits for period $\hat{t}-1$, and a buyer of firm share in period $\hat{t}-1$ receives a share of firm profits for period $\hat{t}$. To aid interpretation, this can be viewed as stock market trade at the end of a period. At the beginning of each period $\hat{t}$, there is a shareholder meeting of existing shareholders; that is, shareholders who bought firm shares at the end of period $\hat{t}-1$. These shareholders are termed period $\hat{t}$ shareholders. At this meeting, managers of firm $\hat{j}$ present period $\hat{t}$ shareholders the production results for period $\hat{t}-1$, and their current and future production plan, denoted $\left(y^{\hat{j}}\right)_{t=\hat{t}}^{T}$. Intuitively, a subset of period $\hat{t}$ shareholders prefers a feasible production plan $y_{\hat{t}}^{\hat{j}}$ to production plan $y_{\hat{t}}^{\hat{j}}$, if they can re-distribute among themselves their period $\hat{t}$ endowments and production plan 
$\hat{y}_{\hat{t}}^{\hat{j}}$ to get new consumption plans for period $\hat{t}$ so that when compared to the consumption plan each could have achieved with her period $\hat{t}$ endowment and her share of profits from production plan $y_{\hat{t}}^{\hat{j}}$, no shareholder in this subset is made worse off with her new consumption plan, some shareholder in this subset is made strictly better off, and shareholders not in this subset are unaffected. For a subset of shareholders to approve production plan $y_{\hat{t}}^{\hat{j}}$, it must be that there is no production plan $y_{\hat{t}}^{\hat{j}}$ that this subset of shareholders prefers to $y_{\hat{t}}^{\hat{j}}$. These ideas are formalized in the following concepts about the consumption preferences of a consumershareholder in a given period, and the production preferences of subsets of shareholders, and it is shown that when $y^{j}=\left(y_{t}^{j}\right)_{t=1}^{T}$ maximizes profits over $Y^{j}$, every subset of shareholders in every period approves this plan. ${ }^{12}$

The idea of making a consumer-shareholder better off in a given period and state can be motivated by considering a consumer-shareholder $i$ with preference relation $\succeq^{i}$, and a consumption plan $x^{i}$, and naturally deriving a preference for consumption in a given period and state as follows. In a particular period $t$, state $s$, consumer-shareholder $i$ prefers a bundle of commodities $x_{t}^{i}(s)$ to $x_{t}^{i}(s)$, if she prefers the consumption plan that is derived from $x^{i}$ by replacing $x_{t}^{i}(s)$ with $\dot{x}_{t}^{i}(s)$ to the consumption plan $x^{i}$. More formally, let $x^{i}$ be a consumption plan for consumer-shareholder $i$, and let $\succeq^{i}$ be the preference of consumer-

\footnotetext{
${ }^{12}$ Notice that the results presented here do not depend on the particular timing of shareholder meetings and stock trade mentioned above. For stock market trade as in Radner (1974), the only interpretive requirement would be that a shareholder meeting is held at least an instant before stock trade, so that shareholders who are to receive profits in a period are the ones voting on firm plans for that period. Conditional on this requirement, shareholder meeting and stock trade can be held at any time during a period. In particular, this applies for an elementary time period, which is also viewed as a node. Similar interpretations naturally hold for cum-dividend stock trading.
} 
shareholder $i$. If $\dot{x}_{\hat{t}}^{i}(\hat{s})$ is a consumption plan for consumer-shareholder $i$ in period $\hat{t}$, state $\hat{s}$, then consumer-shareholder $i$ prefers $\hat{x}_{\hat{t}}^{i}(\hat{s})$ to $x_{\hat{t}}^{i}(\hat{s})$ in period $\hat{t}$, state $\hat{s}$, denoted $\hat{x}_{\hat{t}}^{i}(\hat{s}) \succeq_{\hat{t}}^{i}(\hat{s}) x_{\hat{t}}^{i}(\hat{s})$, if $\hat{x}^{i} \succeq^{i} x^{i}$, where $\hat{x}^{i}$ is defined as follows: $\hat{x}_{t}^{i}(s)=\hat{x}_{t}^{i}(s)$ if $t=\hat{t}$ and $s=$ $\hat{s}$, and $\hat{x}_{t}^{i}(s)=x_{t}^{i}(s)$ otherwise, and consumer-shareholder $i$ strictly prefers $\hat{x}_{\hat{t}}^{i}(\hat{s})$ to $x_{\hat{t}}^{i}(\hat{s})$ in period $\hat{t}$, state $\hat{s}$, denoted $\hat{x}_{\hat{t}}^{i}(\hat{s}) \succ_{\hat{t}}^{i}(\hat{s}) x_{\hat{t}}^{i}(\hat{s})$, if $\hat{x}^{i} \succ^{i} x^{i}$. Let $\succeq^{i}$ be the preference of consumer-shareholder $i$, and let $x^{i}$ be a consumption plan for consumer-shareholder $i$. The preference $\succeq_{t}^{i}(s)$ is weakly monotone in period $t$, state $s$, if for every consumption plan $\dot{x}^{i}$, $\hat{x}_{t}^{i}(s) \gg x_{t}^{i}(s) \Rightarrow \hat{x}_{t}^{i}(s) \succ_{t}^{i}(s) \quad x_{t}^{i}(s)$. Notice that if $\succeq^{i}$ is strongly monotone, then $\succeq_{t}^{i}(s)$ is weakly monotone in period $t$, state $s$, for every period $t$, state $s$. Moreover, if $\succeq_{t}^{i}(s)$ is weakly monotone in period $t$, state $s$, for every period $t$, state $s$, then $\succeq^{i}$ is weakly monotone.

Production preferences of subsets of shareholders are formalized as follows. Let $y=$ $\left(y^{j}\right)_{j=1}^{J}$ be a production profile, and $\left(x^{i}, \theta^{i}\right)_{i=1}^{I}$ be a consumption and shareholding profile. A consumer $i$ is a shareholder of firm $j$ in period $t$, state $s$ if $\theta_{t-1}^{i, j}(s)>0$. For each firm $j$, period $t$, state $s$, let $S_{t}^{j}(s)=\left\{i \mid \theta_{t-1}^{i, j}(s)>0\right\}$ be the collection of shareholders of firm $j$ in period $t$, state $s$. A firm $j$ coalition in period $t$, state $s$, denoted $C_{t}^{j}(s)$, is a nonempty subset of $S_{t}^{j}(s)$. Let $C_{\hat{t}}^{\hat{j}}(\hat{s})$ be a firm $\hat{j}$ coalition in period $\hat{t}$, state $\hat{s}$, let $\hat{y}_{\hat{t}}^{\hat{j}}(\hat{s})$ be a production plan for firm $\hat{j}$ in period $\hat{t}$, state $\hat{s}$, and define $C_{\hat{t}}^{\hat{j}}(\hat{s})$ prefers $y_{\hat{t}}^{\hat{j}}(\hat{s})$ to $y_{\hat{t}}^{\hat{j}}(\hat{s})$, if the production plan $y^{\hat{j}}$ formed by setting $\hat{y}_{t}^{\hat{j}}(s)=\hat{y}_{\hat{t}}^{\hat{j}}(\hat{s})$ if $t=\hat{t}$, and $s=\hat{s}$, and $y_{t}^{\hat{j}}(s)=y_{t}^{\hat{j}}(s)$ otherwise, is feasible, (that is, $\hat{y}^{\hat{j}} \in Y^{\hat{j}}$,) and for every consumer-shareholder $i \in C_{\hat{t}}^{\hat{j}}(\hat{s})$, there is a consumption plan $\dot{x}_{\hat{t}}^{i}(\hat{s})$ in period $\hat{t}$, state $\hat{s}$ such that the production profile $\left(\hat{y}_{\hat{t}}^{j}(\hat{s})\right)_{j=1}^{J}$ in period $\hat{t}$, state $\hat{s}$ formed by setting $\hat{y}_{\hat{t}}^{j}(\hat{s})=\hat{y}_{\hat{t}}^{\hat{j}}(\hat{s})$ if $j=\hat{j}$, and $\hat{y}_{\hat{t}}^{j}(\hat{s})=y_{\hat{t}}^{j}(\hat{s})$ otherwise, and the consumption profile $\left(\hat{x}_{\hat{t}}^{i}(\hat{s})\right)_{i=1}^{I}$ in period $\hat{t}$, state $\hat{s}$ formed by setting $\dot{x}_{\hat{t}}^{i}(\hat{s})=\dot{x}_{\hat{t}}^{i}(\hat{s})$ if $i \in C_{\hat{t}}^{\hat{j}}(\hat{s})$, and $\dot{x}_{\hat{t}}^{i}(\hat{s})=x_{\hat{t}}^{i}(\hat{s})$ otherwise, together form an allocation in period $\hat{t}$, state $\hat{s}$, (that 
is, $\left.\sum_{i=1}^{I} x_{\hat{t}}^{i}(\hat{s})=\sum_{i=1}^{I} w_{\hat{t}}^{i}(\hat{s})+\sum_{j=1}^{J} y_{\hat{t}}^{j}(\hat{s}),\right)$ and for every consumer-shareholder $i \in C_{\hat{t}}^{\hat{j}}(\hat{s})$, $x_{\hat{t}}^{i}(\hat{s}) \succeq_{\hat{t}}^{i}(\hat{s}) x_{\hat{t}}^{i}(\hat{s})$, and for some consumer-shareholder $i \in C_{\hat{t}}^{\hat{j}}(\hat{s}), x_{\hat{t}}^{i}(\hat{s}) \succ_{\hat{t}}^{i}(\hat{s}) x_{\hat{t}}^{i}(\hat{s})$. The first condition ensures that a candidate for a preferred production plan is feasible, the second condition ensures that if the initial production and consumption profiles form an allocation in a given period and state, then the candidate production and consumption profiles remain an allocation in that period and state, and therefore, the candidate consumption and production profiles form a re-distribution that affects at most the shareholders of a particular firm that are in a coalition, and the third condition ensures that nobody in the coalition is made worse off, and someone is made strictly better off. For a firm $j$ coalition in period $t$, state $s, C_{t}^{j}(s)$, a production plan $y^{j}$ is $C_{t}^{j}(s)$-proof if there is no $y_{t}^{j}(s)$ such that $C_{t}^{j}(s)$-prefers $y_{t}^{j}(s)$ to $y_{t}^{j}(s)$. A production plan $y^{j}$ is coalition proof if for every period $t$, state $s$, and for every firm $j$ coalition in period $t$, state $s, C_{t}^{j}(s), y^{j}$ is $C_{t}^{j}(s)$-proof. ${ }^{13}$

The corollary following the lemma and theorem below formalizes the role of profit maximization as a firm objective consistent with shareholder preferences when markets are incomplete and firm shareholders are changing over time.

Lemma. Let $(p, q)$ be a price system, $y=\left(y^{j}\right)_{j=1}^{J}$ be a production profile, $\left(x^{i}, \theta^{i}\right) \in D^{i}(p, q, y)$, and $\dot{x}^{i}$ be another consumption plan for $i$. In period $\hat{t}$, state $\hat{s}$,

$$
\begin{aligned}
& \text { if } x_{\hat{t}}^{i}(\hat{s}) \succeq_{\hat{t}}^{i}(\hat{s}) \quad x_{\hat{t}}^{i}(\hat{s}), \text { then } p_{\hat{t}}(\hat{s}) x_{\hat{t}}^{i}(\hat{s})+q_{\hat{t}}(\hat{s}) \theta_{\hat{t}}^{i}(\hat{s}) \geq W^{i}(p, q, y)_{\hat{t}}(\hat{s}), \quad \text { and } \\
& \text { if } x_{\hat{t}}^{i}(\hat{s}) \succ_{\hat{t}}^{i}(\hat{s}) x_{\hat{t}}^{i}(\hat{s}), \text { then } p_{\hat{t}}(\hat{s}) x_{\hat{t}}^{i}(\hat{s})+q_{\hat{t}}(\hat{s}) \theta_{\hat{t}}^{i}(\hat{s})>W^{i}(p, q, y)_{\hat{t}}(\hat{s}) .
\end{aligned}
$$

Proof. To prove the first statement, suppose its hypothesis is true, and suppose that $p_{\hat{t}}(\hat{s}) \dot{x}_{\hat{t}}^{i}(\hat{s})+q_{\hat{t}}(\hat{s}) \theta_{\hat{t}}^{i}(\hat{s})<W^{i}(p, q, y)_{\hat{t}}(\hat{s})$. Then there is $\hat{x}_{\hat{t}}^{i}(\hat{s}) \gg x_{\hat{t}}^{i}(\hat{s})$ such that $p_{\hat{t}}(\hat{s}) \hat{x}_{\hat{t}}^{i}(\hat{s})+$

\footnotetext{
${ }^{13}$ Notice that definitions regarding coalitions include shareholders of a particular firm. This can be weakened to allow for coalitions of shareholders across firms, as explained in the next section.
} 
$q_{\hat{t}}(\hat{s}) \theta_{\hat{t}}^{i}(\hat{s}) \leq W^{i}(p, q, y)_{\hat{t}}(\hat{s})$. Therefore, if the consumption plan $\hat{x}^{i}$ is defined as $\hat{x}_{t}^{i}(s)=$ $\hat{x}_{\hat{t}}^{i}(\hat{s})$ if $t=\hat{t}$ and $s=\hat{s}$, and $\hat{x}_{t}^{i}(s)=x_{t}^{i}(s)$ otherwise, then $\left(\hat{x}^{i}, \theta^{i}\right) \in B^{i}(p, q, y)$. Moreover, if the consumption plan $\tilde{x}^{i}$ is defined as $\tilde{x}_{t}^{i}(s)=\hat{x}_{t}^{i}(s)$ if $t=\hat{t}$ and $s=\hat{s}$, and $\tilde{x}_{t}^{i}(s)=$ $x_{t}^{i}(s)$ otherwise, then $\hat{x}_{\hat{t}}^{i}(\hat{s}) \gg \hat{x}_{\hat{t}}^{i}(\hat{s})$ implies $\hat{x}^{i} \succ^{i} \tilde{x}^{i}$, and $\hat{x}_{\hat{t}}^{i}(\hat{s}) \succeq_{t}^{i}(s) x_{\hat{t}}^{i}(\hat{s})$ implies $\tilde{x}^{i} \succeq^{i} x^{i}$. Therefore, $\hat{x}^{i} \succ^{i} x^{i}$, contradicting the optimality of $x^{i}$.

To prove the second statement, suppose its hypothesis is true, and suppose that $p_{\hat{t}}(\hat{s}) \dot{x}_{\hat{t}}^{i}(\hat{s})+$ $q_{\hat{t}}(\hat{s}) \theta_{\hat{t}}^{i}(\hat{s}) \leq W^{i}(p, q, y)_{\hat{t}}(\hat{s})$. In this case, if the consumption plan $\tilde{x}^{i}$ is defined as $\tilde{x}_{t}^{i}(s)=$ $\hat{x}_{t}^{i}(s)$ if $t=\hat{t}$ and $s=\hat{s}$, and $\tilde{x}_{t}^{i}(s)=x_{t}^{i}(s)$ otherwise, then $\left(\tilde{x}^{i}, \theta^{i}\right) \in B^{i}(p, q, y)$. Moreover, $\dot{x}_{\hat{t}}^{i}(\hat{s}) \succ_{\hat{t}}^{i}(\hat{s}) x_{\hat{t}}^{i}(\hat{s})$ implies $\tilde{x}^{i} \succ^{i} x^{i}$, contradicting the optimality of $x^{i}$.

Theorem. Let $(p, q)$ be a price system, $y=\left(y^{j}\right)_{j=1}^{J}$ be a production profile, $\left(x^{i}, \theta^{i}\right)_{i=1}^{I}$ be a consumption and shareholding profile, and for every $i,\left(x^{i}, \theta^{i}\right) \in D^{i}(p, q, y)$. For every firm $j$, if $y^{j}$ maximizes profits over $Y^{j}$, then $y^{j}$ is coalition proof.

Proof. Fix $\hat{j}$, suppose $y^{\hat{j}}$ maximizes profits over $Y^{\hat{j}}$, and suppose $y^{\hat{j}}$ is not coalition proof. Let $\hat{t}$ be a period, $\hat{s}$ be a state, $C_{\hat{t}}^{\hat{j}}(\hat{s})$ be a firm $\hat{j}$ coalition in period $\hat{t}$, state $\hat{s}$, and $\hat{y}_{\hat{t}}^{\hat{j}}(\hat{s})$ be a production plan for firm $\hat{j}$ in period $\hat{t}$, state $\hat{s}$ such that $C_{\hat{t}}^{\hat{j}}(\hat{s})$ prefers $\hat{y}_{\hat{t}}^{\hat{j}}(\hat{s})$ to $y_{\hat{t}}^{\hat{j}}(\hat{s})$. For every consumer-shareholder $i \in C_{\hat{t}}^{\hat{j}}(\hat{s})$, let $x_{\hat{t}}^{i}(\hat{s})$ be a consumption plan in period $\hat{t}$, state $\hat{s}$ such that the production profile $\left(\hat{y}_{\hat{t}}^{j}(\hat{s})\right)_{j=1}^{J}$ in period $\hat{t}$, state $\hat{s}$ formed by setting $y_{\hat{t}}^{j}(\hat{s})=y_{\hat{t}}^{\hat{j}}(\hat{s})$ if $j=\hat{j}$, and $\hat{y}_{\hat{t}}^{j}(\hat{s})=y_{\hat{t}}^{j}(\hat{s})$ otherwise, and the consumption profile $\left(\hat{x}_{\hat{t}}^{i}(\hat{s})\right)_{i=1}^{I}$ in period $\hat{t}$, state $\hat{s}$ formed by setting $\dot{x}_{\hat{t}}^{i}(\hat{s})=\dot{x}_{\hat{t}}^{i}(\hat{s})$ if $i \in C_{\hat{t}}^{\hat{j}}(\hat{s})$, and $\dot{x}_{\hat{t}}^{i}(\hat{s})=x_{\hat{t}}^{i}(\hat{s})$ otherwise, together form an allocation in period $\hat{t}$, state $\hat{s},\left(\sum_{i=1}^{I} \dot{x}_{\hat{t}}^{i}(\hat{s})=\sum_{i=1}^{I} w_{\hat{t}}^{i}(\hat{s})+\sum_{j=1}^{J} y_{\hat{t}}^{j}(\hat{s}),\right)$ and for every consumer-shareholder $i \in C_{\hat{t}}^{\hat{j}}(\hat{s}), x_{\hat{t}}^{i}(\hat{s}) \succeq_{\hat{t}}^{i}(\hat{s}) x_{\hat{t}}^{i}(\hat{s})$, and for some consumershareholder $i \in C_{\hat{t}}^{\hat{j}}(\hat{s}), x_{\hat{t}}^{i}(\hat{s}) \succ_{\hat{t}}^{i}(\hat{s}) x_{\hat{t}}^{i}(\hat{s})$. Then, by the lemma above, for every consumer- 
shareholder $i \in C_{\hat{t}}^{\hat{j}}(\hat{s}), p_{\hat{t}}(\hat{s}) x_{\hat{t}}^{i}(\hat{s})+q_{\hat{t}}(\hat{s}) \theta_{\hat{t}}^{i}(\hat{s}) \geq W^{i}(p, q, y)_{\hat{t}}(\hat{s})$, and for some consumershareholder $i \in C_{\hat{t}}^{\hat{j}}(\hat{s}), p_{\hat{t}}(\hat{s}) x_{\hat{t}}^{i}(\hat{s})+q_{\hat{t}}(\hat{s}) \theta_{\hat{t}}^{i}(\hat{s})>W^{i}(p, q, y)_{\hat{t}}(\hat{s})$. Therefore,

$$
\begin{aligned}
\sum_{i} p_{\hat{t}}(\hat{s}) w_{\hat{t}}^{i}(\hat{s})+\sum_{j} p_{\hat{t}}(\hat{s}) y_{\hat{t}}^{j}(\hat{s})+\sum_{i} q_{\hat{t}}(\hat{s}) \theta_{\hat{t}}^{i}(\hat{s}) \\
\quad=\sum_{i}\left(p_{\hat{t}}(\hat{s}) x_{\hat{t}}^{i}(\hat{s})+q_{\hat{t}}(\hat{s}) \theta_{\hat{t}}^{i}(\hat{s})\right) \\
>\sum_{i} W^{i}(p, q, y)_{\hat{t}}(\hat{s}) \\
=\sum_{i}\left(p_{\hat{t}}(\hat{s}) w_{\hat{t}}^{i}(\hat{s})+q_{\hat{t}}(\hat{s}) \theta_{\hat{t}-1}^{i}(\hat{s})+\sum_{j} \theta_{\hat{t}-1}^{i, j}(\hat{s}) p_{\hat{t}}(\hat{s}) y_{\hat{t}}^{j}(\hat{s})\right) \\
=\sum_{i} p_{\hat{t}}(\hat{s}) w_{\hat{t}}^{i}(\hat{s})+\sum_{i} q_{\hat{t}}(\hat{s}) \theta_{\hat{t}-1}^{i}(\hat{s})+\sum_{j} p_{\hat{t}}(\hat{s}) y_{\hat{t}}^{j}(\hat{s}),
\end{aligned}
$$

whence $p_{\hat{t}}(\hat{s}) \dot{y}_{\hat{t}}^{\hat{j}}(\hat{s})>p_{\hat{t}}(\hat{s}) y_{\hat{t}}^{\hat{j}}(\hat{s})$, and consequently, $\sum_{t, s} p_{t}(s) \dot{y}_{t}^{\hat{j}}(s)>\sum_{t, s} p_{t}(s) y_{t}^{\hat{j}}(s)$, contradicting the hypothesis that $y^{\hat{j}}$ maximizes profits over $Y^{\hat{j}}$.

Corollary. If $\left(p, q ; y=\left(y^{j}\right)_{j=1}^{J} ;\left(x^{i}, \theta^{i}\right)_{i=1}^{I}\right)$ is a Radner equilibrium, then for every $j, y^{j}$ is coalition proof.

This corollary formalizes profit maximization as a firm objective consistent with shareholder preferences when markets are incomplete and firm shareholders are changing over time. As described above, the consistency of profit maximization can also be viewed from the perspective of sequential shareholder evaluation, as follows. When presented with a profit-maximizing production plan for firm $j, y^{j}=\left(y_{t}^{j}\right)_{t=1}^{T}$, shareholders given by the shareholding endowment unanimously approve $y_{1}^{j}(s)$ as a production plan in period 1 , state $s$, and when presented with $\left(y_{t}^{j}\right)_{t=2}^{T}$, shareholders in period 2 , state $s$ unanimously approve $y_{2}^{j}(s)$ as a production plan in period 2 , state $s$, and continuing in a similar manner, when presented with $\left(y_{t}^{j}\right)_{t=\hat{t}}^{T}$, shareholders in period $\hat{t}$, state $s$ unanimously approve $y_{\hat{t}}^{j}(s)$ as a production plan in period $\hat{t}$, state $s$. This is true regardless of which state of the world is realized. In this sense, a profit-maximizing production plan survives sequential shareholder evaluation 
along the equilibrium path.

It is noteworthy that the result presented above is independent of particular voting requirements; that is, this result is independent of what share of the firm is required of a coalition before it can affect firm decisions, and consequently, this result applies even when shareholders with a small share of the firm can affect firm decisions.

\section{Some Extensions}

The consistency of profit maximization is shown above for the case where shareholders of a particular firm in a particular period (and state) can form coalitions, and for the case where shareholders have a claim on next period's (same state's) production plan. Both these conditions can be relaxed, so that profit maximization remains a consistent firm objective when shareholders of different firms in a particular period (and state) can form a coalition across firms, and when shareholders in a firm in a particular period (and state) have a claim to that period's (and state's) production plan, as follows.

Profit maximization remains a consistent firm objective when shareholders can form coalitions across firms. This can be seen by an appropriate modification of the definition of a coalition, and a re-formulation of production preferences of coalitions of shareholders across firms, as follows.

Let $y=\left(y^{j}\right)_{j=1}^{J}$ be a production profile, and $\left(x^{i}, \theta^{i}\right)_{i=1}^{I}$ be a consumption and shareholding profile, and for each firm $j$, period $t$, state $s$, let $S_{t}^{j}(s)$ be the collection of shareholders of firm $j$ in period $t$, state $s$, and $C_{t}^{j}(s)$ be a (possibly empty) firm $j$ coalition in period $t$, state $s$. A coalition in period t, state $s$ is a non-empty union of firm coalitions in 
period $t$, state $s$, denoted $C_{t}(s)=\bigcup_{j} C_{t}^{j}(s)$. Let $C_{\hat{t}}(\hat{s})$ be a coalition in period $\hat{t}$, state $\hat{s}$, let $\left(\hat{y}_{\hat{t}}^{j}(\hat{s}): j\right.$ satisfies $\left.C_{\hat{t}}^{j}(\hat{s}) \neq \emptyset\right)$ be a collection of production plans in period $\hat{t}$, state $\hat{s}$, and define $C_{\hat{t}}(\hat{s})$ prefers $\left(\hat{y}_{\hat{t}}^{j}(\hat{s}): j\right.$ satisfies $\left.C_{\hat{t}}^{j}(\hat{s}) \neq \emptyset\right)$ to $\left(y_{\hat{t}}^{j}(\hat{s}): j\right.$ satisfies $\left.C_{\hat{t}}^{j}(\hat{s}) \neq \emptyset\right)$, if the production profile $\left(\hat{y}^{j}: j\right.$ satisfies $\left.C_{\hat{t}}^{j}(\hat{s}) \neq \emptyset\right)$ formed by setting for every $j$ such that $C_{\hat{t}}^{j}(\hat{s}) \neq \emptyset, \hat{y}_{t}^{j}(s)=\dot{y}_{\hat{t}}^{j}(\hat{s})$ if $t=\hat{t}$, and $s=\hat{s}$, and $\hat{y}_{t}^{j}(s)=y_{t}^{j}(s)$ otherwise, is feasible, (that is, for every $j$ such that $C_{\hat{t}}^{j}(\hat{s}) \neq \emptyset, \hat{y}^{j} \in Y^{j}$,) and for every consumer-shareholder $i \in C_{\hat{t}}(\hat{s})$, there is a consumption plan $x_{\hat{t}}^{i}(\hat{s})$ in period $\hat{t}$, state $\hat{s}$ such that the production profile $\left(\hat{y}_{\hat{t}}^{j}(\hat{s})\right)_{j=1}^{J}$ in period $\hat{t}$, state $\hat{s}$ formed by setting $\dot{y}_{\hat{t}}^{j}(\hat{s})=\hat{y}_{\hat{t}}^{\hat{j}}(\hat{s})$ if $j$ satisfies $C_{\hat{t}}^{j}(\hat{s}) \neq \emptyset$, and $\dot{y}_{\hat{t}}^{j}(\hat{s})=y_{\hat{t}}^{j}(\hat{s})$ otherwise, and the consumption profile $\left(\hat{x}_{\hat{t}}^{i}(\hat{s})\right)_{i=1}^{I}$ in period $\hat{t}$, state $\hat{s}$ formed by setting $\hat{x}_{\hat{t}}^{i}(\hat{s})=\dot{x}_{\hat{t}}^{i}(\hat{s})$ if $i \in C_{\hat{t}}(\hat{s})$, and $\dot{x}_{\hat{t}}^{i}(\hat{s})=x_{\hat{t}}^{i}(\hat{s})$ otherwise, together form an allocation in period $\hat{t}$, state $\hat{s}$, (that is, $\left.\sum_{i=1}^{I} x_{\hat{t}}^{i}(\hat{s})=\sum_{i=1}^{I} w_{\hat{t}}^{i}(\hat{s})+\sum_{j=1}^{J} \hat{y}_{\hat{t}}^{j}(\hat{s}),\right)$ and for every consumershareholder $i \in C_{\hat{t}}(\hat{s}), x_{\hat{t}}^{i}(\hat{s}) \succeq_{\hat{t}}^{i}(\hat{s}) x_{\hat{t}}^{i}(\hat{s})$, and for some consumer-shareholder $i \in C_{\hat{t}}(\hat{s})$, $\hat{x}_{\hat{t}}^{i}(\hat{s}) \succ_{\hat{t}}^{i}(\hat{s}) x_{\hat{t}}^{i}(\hat{s})$. The first condition ensures that a candidate for a preferred collection of production plans is feasible for every firm that has a shareholder in the coalition, the second condition ensures that if the initial production and consumption profiles form an allocation in a given period and state, then the candidate production and consumption profiles remain an allocation in that period and state, and therefore, the candidate consumption and production profiles form a re-distribution that affects at most shareholders in a coalition, and the third condition ensures that nobody in the coalition is made worse off, and someone is made strictly better off. For a coalition in period $t$, state $s, C_{t}(s)$, a production profile $\left(y^{j}\right)_{j=1}^{J}$ is $C_{t}(s)$-proof if there is no $\left(\dot{y}_{t+1}^{j}(s): j\right.$ satisfies $\left.C_{t}^{j}(s) \neq \emptyset\right)$ such that $C_{t}(s)$ prefers $\left(\dot{y}_{t+1}^{j}(s)\right.$ : $j$ satisfies $\left.C_{t}^{j}(s) \neq \emptyset\right)$ to $\left(y_{t+1}^{j}(s): j\right.$ satisfies $\left.C_{t}^{j}(s) \neq \emptyset\right)$. A production profile $\left(y^{j}\right)_{j=1}^{J}$ is coalition proof if for every period $t$, state $s$, and for every coalition in period $t$, state $s$, 
$C_{t}(s),\left(y^{j}\right)_{j=1}^{J}$ is $C_{t}(s)$-proof.

With this notation and terminology, the statement and proof of the lemma presented above remain true. The first line in the statement of the theorem remains the same, and the second line is modified to read, "If $\left(y^{j}\right)_{j=1}^{J}$ maximizes profits over $\left(Y^{j}\right)_{j=1}^{J}$, then $\left(y^{j}\right)_{j=1}^{J}$ is coalition proof." Here $\left(y^{j}\right)_{j=1}^{J}$ maximizes profits over $\left(Y^{j}\right)_{j=1}^{J}$ means that for every $j, y^{j}$ maximizes profits over $Y^{j}$. The proof of the theorem needs obvious modifications; one useful modification is to notice that in the last line, after "whence" the words "for some $\hat{j}$ such that $C_{t}^{\hat{j}}(s) \neq \emptyset$ " should be added. The corollary is then modified to state, "If $\left(p, q ; y=\left(y^{j}\right)_{j=1}^{J} ;\left(x^{i}, \theta^{i}\right)_{i=1}^{I}\right)$ is a Radner equilibrium, then $\left(y^{j}\right)_{j=1}^{J}$ is coalition proof."

Profit maximization remains a consistent firm objective with cum-dividend stock trading. This can be seen by an appropriate modification of a consumer-shareholder's budget set, and the definition of coalition proof, as follows.

A consumer-shareholder's budget set is modified as follows. For a price system $(p, q)$, a production profile $y=\left(y^{j}\right)_{j=1}^{J}$, and a consumption-shareholding plan $\left(x^{i}, \theta^{i}\right)$ for consumershareholder $i$, the disposable income of $i$ in period $t$, state $s$ is

$$
W^{i}(p, q, y)_{t}(s)=p_{t}(s) w_{t}^{i}(s)+q_{t}(s) \theta_{t-1}^{i}(s)+\sum_{j} \theta_{t}^{i, j}(s) p_{t}(s) y_{t}^{j}(s) .
$$

In this setting, a $\theta_{t}^{i, j}(s)$ shareholding by consumer-shareholder $i$ in firm $j$ in period $t$, state $s$ provides her with a $\theta_{t}^{i, j}(s)$ share of profits of firm $j$ in the same period $t$, state $s$, (and she continues to receive a share of profits in future periods to the extent that she continues shareholding in this firm. $)^{14} \mathrm{~A}$ consumption-shareholding plan $\left(x^{i}, \theta^{i}\right)$ is $(p, q, y)$-affordable for consumer-shareholder $i$, if in every period $t$, state $s, p_{t}(s) x_{t}^{i}(s)+q_{t}(s) \theta_{t}^{i}(s) \leq W^{i}(p, q, y)_{t}(s)$.

\footnotetext{
${ }^{14}$ Notice that for $t=T, \theta_{T}^{i, j}(s)$ is identically 0 , so a coalition (a non-empty subset of shareholders with positive shareholding) is not defined. There are some obvious alternatives in this case; as $q_{T}(s)$ is also
} 
The budget set and demand set are now defined as in the previous section, as are the notion of a Radner-GEI economy, and a Radner equilibrium.

Shareholder control is formalized with the same assumptions as in the previous section, except that for the formal analysis, shareholders in a particular period who can credibly affect the firm's production plan in that period are the after-trade shareholders. (It is these shareholders who receive firm profits in a given period.) To aid interpretation, this can be viewed as stock-market trade at any moment before a shareholder meeting. Shareholder control is exercised in a manner similar to that described in the previous section. Production preferences of subsets of shareholders are formalized as above, but with the modification that the collection of shareholders of firm $j$ in period $t$, state $s$ is given by $S_{t}^{j}(s)=\left\{i \mid \theta_{t}^{i, j}(s)>0\right\}$. The remaining notation and terminology for coalition proof is unaffected. With this new notation and terminology, the statement and proof of the lemma remain true. The statement of the theorem remains the same, and it is proved with the obvious modification in the time index for shareholdings. The corollary is unaffected.

It is easy to appropriately extend the result to the case where short sales in firm shares are permitted, and when assets in addition to firm shares are available. Moreover, the extensions mentioned above can also be combined to prove, for example, the consistency of profit maximization with coalitions of shareholders across firms and with cum-dividend stock trading.

identically zero, one alternative is to restrict the definition of coalition proof to $t \leq T-1$; another alternative is to restrict a firm's planning horizon to $T-1$, so that for every $j, y_{T}^{j}(s)$ is identically zero. 


\section{Conclusion}

The analysis presented above shows that profit maximization can be consistent with shareholder preferences and shareholder control in private ownership economies with incomplete markets and sequential trade, in the sense that along the equilibrium path, in every time period and state of the world, every coalition of a firm's shareholders in that time period and state of the world approves a profit-maximizing production plan. The intuition for this result is similar to the intuition for the result for Arrow-Debreu economies; that is, a profitmaximizing production plan provides a maximal extension of every consumer-shareholder's budget set in each period and state in which a consumer-shareholder can affect production choices, and therefore, if a consumer-shareholder is optimizing over such a budget set, another production plan cannot improve upon this outcome. The analysis here deduces the consistency of profit-maximization by incorporating some basic implications of a relatively realistic process of shareholder control, by deriving shareholder preferences for production plans from more primitive consumer preferences, and by evaluating different production plans using such shareholder preferences along any path that might be realized in equilibrium. The result presented here applies to decentralized, private ownership economies with anonymous stock market trade over time, and with firm ownership separate from control.

The analysis presented above shows that with profit maximization as a firm objective, firm production over time can be consistently organized even when firm shareholders are changing over time. In particular, with the given assumptions, this objective is unanimously supported by a firm's shareholders, it allows for a separation of ownership and control, thereby facilitating the anonymity and smooth operation of decentralized markets, and it does not require a 
firm manager to possess more analytical ability than a consumer-shareholder. Moreover, this objective does not impose additional informational requirements that arise when firms maximize present value based on shareholder inter-temporal rates of substitution. Finally, this objective helps provide a foundation for formulating a theory of the firm in economies with incomplete markets; a theory based on primitives of shareholder preferences and shareholder control that are to be necessarily satisfied in economies with private firm ownership. 


\section{References}

Bonnisseau, J.-M., And O. Lachiri (2003): "Dreze's Criterion in a Multi-Period Economy With Stock Markets," Mimeo. Université Paris.

Diamond, P. A. (1967): "The Role Of a Stock Market In a General Equilibrium Model With Technological Uncertainty," American Economic Review, 57(4), 759-776.

Dierker, E., H. Dierker, and B. Grodal (2002): "Non-Existence of Constrained Efficient Equilibria When Markets are Incomplete," Econometrica, 70(3), 1245-1251.

Dierker, E., And B. Grodal (1996): "Profit Maximization Mitigates Competition," Economic Theory, 7(1), 139-160.

(1999): "The Price Normalization Problem in Imperfect Competition and the Objective of the Firm," Economic Theory, 14(2), 257-284.

Drèze, J. H. (1974): "Investment Under Private Ownership: Optimality, Equilibrium, and Stability," in Allocation under Uncertainty: Equilibrium and Optimality, ed. by J. H. Drèze, pp. 129-165. Wiley, New York.

Duffie, D., And W. Shafer (1985): "Equilibrium in Incomplete Markets: I: A Basic Model of Generic Existence," Journal of Mathematical Economics, 14(3), 285-300.

(1986): "Equilibrium in Incomplete Markets: II: Generic Existence in Stochastic Economies," Journal of Mathematical Economics, 15(3), 199-216.

Ekern, S., And R. Wilson (1974): "On the Theory of the Firm In an Economy With Incomplete Markets," The Bell Journal of Economics and Management Science, 5(1), 171-180.

Geanakoplos, J., M. Magill, M. QuinziI, and J. Drèze (1990): "Generic Inefficiency of Stock Market Equilibrium When Markets are Incomplete," Journal of Mathematical Economics, 19(1), 113-151.

Geanakoplos, J., and H. Polemarchakis (1986): "Existence, Regularity, and Constrained Suboptimality of Competitive Allocations when Markets are Incomplete," in Uncertainty, Information, and Communication: Essays in Honor of Kenneth Arrow, Vol. 3, ed. by W. P. Heller, R. M. Starr, and D. A. Starrett, pp. 65-95. Cambridge University Press.

Grossman, S. J., and O. D. Hart (1979): "A Theory of Competitive Equilibrium in Stock Market Economies," Econometrica, 47(2), 293-330.

Hart, O. (1975): "On the Optimality of Equilibrium when the Market Structure is Incomplete," Journal of Economic Theory, 11(3), 418-443.

Magill, M., And M. QuinzII (1996): Theory of Incomplete Markets. MIT Press. 
Radner, R. (1972): "Existence of Equilibrium of Plans, Prices, and Price Expectations in a Sequence of Markets," Econometrica, 40(2), 289-303.

(1974): "A Note on Unanimity of Stockholders' Preferences Among Alternative Production Plans: A Reformulation of the Ekern-Wilson Model," The Bell Journal of Economomics and Management Science, 5(1), 181-184.

Sabarwal, T. (2003): "On the Allocative Efficiency of Competitive Prices in Economies With Incomplete Markets," Mimeo. The University of Texas at Austin.

Stiglitz, J. E. (1982): "The Inefficiency of Stock Market Equilibrium," The Review of Economic Studies, 49, 241-261. 